\section{Wildlife use in the Neotropics}

Humans have always had a complicated relationship with animals. Animals were food, domesticates, predators and competitors. Whatever the relationship, animals were and continue to be vital for human survival in many parts of the world, particularly in tropical regions. Until recently, conservation interest in the Neotropics has largely ignored the importance wild animals play in the daily lives of rural people (Redford, 1993). Interest in the 'benefits' to be gained from tropical regions, particularly forested ones, have concentrated on products from plants. In the Neotropics, wild animals have rarely been included in calculations of 'forest value' or listed in benefits to be derived from the forest, to say nothing of non-forest areas where less work has been done. Free-ranging wildlife, particularly that used for subsistence consumption, has remained a shadow 'subsidy from nature' (Hecht et al., 1988), undervalued by those who are often most influential in deciding the fate of the habitats, the animals and the people.

However, even if wildlife were valued appropriately, populations would probably still be susceptible to local extinctions due to a lack of management alternatives, particularly with regard to subsistence hunting. The lack of management of wildlife populations throughout many regions of the Neotropics is not only causing the depletion of animal populations, but is also compromising the long-term socioeconomic benefits that wildlife offers.

It is not the case that wildlife management cannot work in the Neotropics; it surely can function, as it has in many countries throughout the world. There are a range of different management systems that can work under different situations for the Neotropics. Indeed, wildlife management has taken many forms in European and North American countries with consistent results - an increase in wildlife populations. In the Neotropics wildlife management might revolve around rural communities in some cases, and private landholders in other cases. The intent should be to set up wildlife-management systems and avoid unmanaged systems.
This special issue of Oryx features studies that examine wildlife use in the Neotropics. It is clear from the papers presented that a growing interest in defining the value of wildlife in the Neotropics has resulted in an increase in studies examining relevant aspects of wildlife use. But answers for wildlife management in the Neotropics are not always straightforward; information must be obtained not only on the biology of species populations but also on the socio-economic realities of people using wildlife, as well as the national and international policies and politics that affect such management. As these papers clearly show, people who most rely on wildlife are often indigenous groups or non-tribal rural people. Wildlife management systems, if they are to succeed, must therefore integrate these people. In addition, indigenous and non-tribal peoples often use wildlife in different ways. For example, indigenous people commonly use a broader range of species than non-tribal hunters. These differences clearly require different management schemes as well as an appreciation of social factors.

The importance of the ongoing studies of wildlife use in the Neotropics is not only that it will give a truer picture of the value of wildlife but, more importantly, that it will lead to wildlife-management systems that conserve animal populations. Although only a subset of the work currently addressing wildlife use in the Neotropics, these papers provide a glimpse of the richness, variety and importance of such work.

Kent Redford, The Nature Conservancy, 1815 North Lynn Street, Arlington, VA 2220, USA Richard E. Bodmer, University of Florida, Gainesville, FL 32611, USA

\section{References}

Hecht, S.B., Anderson, A. and May, P. 1988. The subsidy from nature: shifting cultivation, successional palm forests and rural development. Human Organization, 49, 25-35.

Redford, K.H. 1993. Hunting in neotropical forests: a subsidy from nature. In Tropical Forests, People and Food (eds C. M. Hladik, A. Hladik, O. F. Linares, H. Pagezy, A. Semple and M. Hadley), Man and the Biosphere Series, Vol. 13, pp. 227-246. UNESCO, Paris. 